\title{
PENGARUH VARIASI PANJANG PIPA ISAP FLUSHING CONDUIT TERHADAP VOLUME PENGGELONTORAN SEDIMEN DI WADUK (UJI EKSPERIMENTAL)
}

\author{
Amrullah Mansida ${ }^{1)}$ La Mut $^{2)}$ dan Irmawati ${ }^{3)}$ \\ ${ }^{1}$ Universitas Muhammadiyah Makassar, Indonesia \\ Email : amrullahmansida@yahoo.co.id \\ ${ }^{2}$ Universitas Muhammadiyah Makassar, Indonesia \\ Email : lamut1884@gmail.com \\ ${ }^{3}$ Universitas Muhammadiyah Makassar, Indonesia \\ Email : irmawati1938@gmail.com
}

\begin{abstract}
Abstrak
Penelitian ini bertujuan untuk mengetahui kinerja metode flushing conduit terhadap volume penggelontoran sedimen apabila panjang pipa isapnya divariasikan. Karakteristik sedimen yang digunakan dalam penelitian ini adalah pasir sedang berdasarkan skala wentworth dari hasil analisa saringan. Dari hasil penelitian menunjukan jumlah sedimen yang tergelontor untuk $Q_{1}$ yaitu pada panjang pipa isp $0,5 \mathrm{~cm}$ jumlah volume gelontor $\left(v_{g}\right) 0,0073 \mathrm{~m}^{3}$, panjang pipa isap 1,5 cm jumlah Volume tergelontor $\left(v_{g}\right) 0,0064 \mathrm{~m}^{3}$ dan pada panjang pipa isap 2,5 $\mathrm{cm}$ jumlah volume gelontor $\left(v_{g}\right)$ yaitu $0,0060 \mathrm{~m}^{3}$. Kinerja Flushing Conduit menunjukan semakin pendek pipa isap yang digunakan maka volume gelontor yang dihasilkan semakin banyak hal ini dipengaruhi oleh jarak antar sedimen dengan pipa flushing yang semakin jauh jaraknya maka akan semakin memperlambat proses sedimen masuk kedalam pipa flushing. Mekanisme kerja flushing conduit terbagi atas tiga tahapan yaitu memberikan tekanan sehingga terjadi fluidasi, proses penghisapan endapan sedimen masuk kedalam pipa akibat fluktuasi debit dan tekanan, serta transportasi sedimen dalam pipa.
\end{abstract}

kata kunci : Waduk, Sedimentasi, Flushing Conduit.

\begin{abstract}
This study aims to determine the performance of the flushing conduit method against the volume of sediment displacement when the length of the suction pipe is varied. The sediment characteristic used in this research is the medium sand based on goworth scale from the result of filter analysis. The results showed that the amount of sediment that was flushed for Q1 was $0,5 \mathrm{~cm}$ length of the isp number of volume of gelontor volume (vg) $0,0073 \mathrm{~m}^{3}$, the suction tube length of $1,5 \mathrm{~cm}$ the volume amount was flushed (vg) 0,0064 $\mathrm{m}^{3}$ and at length suction pipe $2,5 \mathrm{~cm}$ the volume amount of gelontor $(\mathrm{vg})$ is $0,0060 \mathrm{~m}^{3}$. Flushing Conduit performance shows the shorter suction pipe that is used then the volume of gelontor produced more and more is influenced by the distance between the sediments with the flushing pipe that the further distance it will further slow the process of sediment into the flushing pipe. Working mechanism of flushing conduit is divided into three stages, namely to provide pressure so that fluidation occurs, sediment sediment absorption process into the pipe due to fluctuations in flow and pressure, as well as sediment transport in the pipeline.
\end{abstract}

keywords: Dam, Sedimentation, Flushing Conduit. 


\section{PENDAHULUAN}

Daerah aliran sungai (DAS) adalah suatu wilayah daratan yang secara topografik dibatasi oleh punggungpunggung gunung yang menampung dan menyimpan air hujan untuk kemudian menyalurkan ke laut melalui sungai utama (Chay Asdak, 2010).

Sedimen yang diendapkan dalam kolam waduk biasanya disebarkan di bawah elevasi air normal, tetapi air yang banyak mengandung sedimen disimpan sementara dalam volume pengendalian banjir di atas elevasi air normal cukup lama, sehingga sebagian dari sedimen akan mengendap pada elevasi kolam pengendali banjir.

Usaha yang bisa dilakukan untuk mengatasi permasalahan sedimentasi didalam saluran floodway adalah dengan melakukan pembilasan atau penggelontoran sedimen secara hidrolis (hydraulic flushing). penggelontoran sedimen secara hidraulis (Hydraulic flushing) adalah cara yang lebih baik untuk mengembalikan kapasitas reservoir bila dibandingkan dengan cara lain seperti penggalian atau pengerukan secara manual (Dreedging) sehingga konsep flushing conduit (penggelontoran sedimen dalam pipa) adalah solusi yang tepat dalam pengendalian sedimen yang ramah lingkungan dan relatif murah.

\section{Proses Sedimentasi}

Proses sedimentasi dapat terjadi pada lahan-lahan pertanian maupun di sepanjang dasar sunga, dasar waduk, muara, dan sebagainya. Berdasarkan proses terjadinya sedimentasi dapat dibedakan menjadi dua bagian yaitu:

a) Proses Sedimentasi secara Geologis (Normal)

b) Proses Sedimentasi Dipercepat

\section{Kapasitas Waduk}

Kapasitas waduk saat direncanakan berdasarkan perhitungan volume tampungan air tanpa adanya sedimentasi.

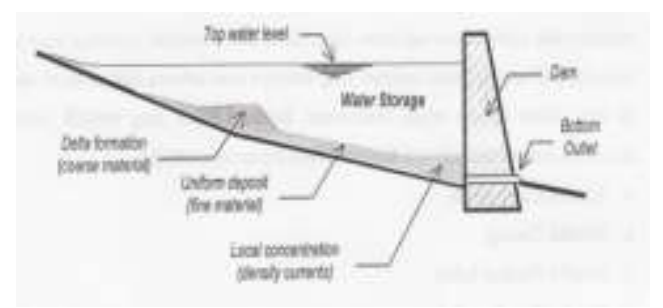

\section{Gambar 1. Berkurangnya kapasitas Waduk}

kapasitas waduk secara umum dibedakan menjadi tiga yaitu :

a) Kapsitas mati (dead storage)

b) Kapasitas pelayanan (Active Storage)

c) Kapasitas total

Umur pelayanan waduk merupakan fungsi dari volume tampungan aktif (Ilyas et al., 1991). Semakin menyusut 
volume tampungan aktif menandakan semakin pendek umur pelayanan waduk. Pelayanan volume tampungan aktif lebih banyak disebabkan karena bertambahnya volume sedimen yang masuk kedalam waduk.

\section{Dsitribusi Ukuran Butir Sedimen}

Tabel 1. Klasifikasi ukuran butir $\frac{\text { sedimen menurut skala Wentworth }}{\text { Klasifikasi }}$

\begin{tabular}{ccc}
\hline \multirow{3}{*}{ Berangkal } & Sangat besar & $4096-2048$ \\
& Besar & $2048-1024$ \\
& Sedang & $1024-512$ \\
& Kecil & $512-256$ \\
\hline Kerakal & Besar & $256-128$ \\
& Kecil & $128-64$ \\
\hline \multirow{3}{*}{ Koral (Kerikil besar) } & Sangat besar & $64-32$ \\
& Kasar & $32-16$ \\
& Sedang & $16-8$ \\
& Halus & $8-4$ \\
\hline Kerikil & & $4-2$ \\
& & \\
\hline \multirow{4}{*}{ Pasir } & Sangat besar & $1-1$ \\
& Kasar & $1-0,5$ \\
& Sedang & $0,5-0,25$ \\
& Halus & $0,25-0,125$ \\
& Sangat Halus & $0,125-0,062$ \\
\hline Lumpur & Kasar & $0,062-0,031$ \\
& & \\
\hline & Sedang & $0,031-0,016$ \\
& Halus & $0,016-0,008$ \\
& Sangat Halus & $0,008-0,004$ \\
\hline \multirow{2}{*}{ Lempung } & Kasar & $0,004-0,002$ \\
& Sedang & $0,002-0,001$ \\
& Halus & $0,001-0,0005$ \\
& Sangat Halus & $0,0005-0,00024$ \\
\hline
\end{tabular}

Sumber : Muhammad Arsyad Thaha (2006)

Penggelontoran Sedimen Dengan

\section{Metode Flushing}

Prinsip dari metode penggelontoran sedimen dengan energi potensia air waduk (flushing) adalah mengeluarkan sedimen dengan mengambil manfaat energi hidrolik akibat beda tinggi antara muka air di depan dan belakang bendungan, untuk mensuplai energi pada sediment flushing system.

Metode flushing counduit atau pengurasan melalui pipa dengan memanfaatkan fluktuasi tekanan untuk mengusik endapan sedimen sehingga terfluidasi, dan selanjutnya terhisap ke dalam pipa melalui lubang kecil kemudian terjadi transpor endapan sedimen dalam pipa.

\section{Perbedaan Mekanisme kerja Fluidasi}

\section{dengan flushing Conduit}

Tabel 2. Perbedaan metode kerja fluidasi dengan flushing conduit

$$
\begin{aligned}
& \begin{array}{lll}
\hline \text { No. } & \text { Metode Fluidasi } & \text { Metode flushing conduit } \\
\hline
\end{array} \\
& \text { 1. Mengendalikan aliran permukaan Mengendalikan aliran dalam pipa } \\
& \text { yang lebih dalam ke daerah lebih dalam } \\
& \text { Mengandalkan pancaran jet Mengandalkan hisapan sedimen } \\
& \text { 2. melalui lubang perforasi untuk melalui lubang isap ke dalam pipa } \\
& \text { mengusik dan mengangkat dan transpor sedimen dalam pipa } \\
& \text { sedimen } \\
& \text { 3. Membutuhkan tekanan yang besar Membutuhkan tekanan fluktuaktif } \\
& \text { Membutuhkan debit yang relatif Membutuhkan debit yang relatif } \\
& 4 \text { besar besar } \\
& \text { Sistem pengaliran dilakukan Sistem pengaliran dilakukan } \\
& \text { 5. dengan pengaliran bebas dengan pengaliran bertekanan } \\
& \text { Tekanan dsalam pipa harus lebih Tekanan dalam pipa harus lebih } \\
& \text { 6. besar daripada di luar pipa rendah dari pada luar pipa }
\end{aligned}
$$

\section{Aliran Dalam Saluran Tertutup (PIPA)}

Aliran dalam pipa berfungsi untuk memindahkan fluida dari suatu tempat ke tempat yang lain. Pada umumnya fluida yang akan dipindahkan memiliki nilai kekentalan yang berbeda-beda. Nilai kekentalan ini sangat penting untuk diketahui agar dapat menentukan kebutuhan energi yng diperlukan.

Perbedaan mendasar antara aliran pada saluran terbuka dan saluran 
tertutup (aliran pada pipa) adalah adanya permukaan yang bebas dan (hampir selalu) berupa udara pada saluran terbuka. Jadi seandainya pada pipa alirannya tidak penuh hingga masih ada rongga yang berisi udara maka sifat dan karaktersitik alirannya sama dengan aliran pada saluran terbuka.

Kehilangan Tinggi Tenaga Pada

\section{Lapisan Sedimen}

Kecepatan aliran pada sumbu jet sama dengan kecepatan jet dilubang. Tinggi $z_{1}$ sangat dipengaruhi oleh turbulensi dan gesekan antara jet dengan fraksi solid dan fluida yang ada disekitar. Pada fenomena antara fluidisasi dan flushing tinggi $z_{1}$ relatif kecil karena gesekan sedimen disekitarnya sehingga dapat dianggap tidak signifikan terhadap ketebalan sedimen. Dengan demikian, beban sedimen yang diperhitungkan dapat berbentuk slinder sehingga $d_{b}$ dan berdiamter $d_{c}$. Kehilangan tinggi tenaga oleh lapisan sedimen selanjutnya dapat ditentukan dengan meninjau keseimbangan gaya vertical antara gaya keatas ( $. g . h . A)$ dengan berat sedimen dalam air $\left(\mathrm{d}_{\mathrm{b}}(1-\varepsilon) A\left(\rho_{s}-\rho\right) / \rho\right.$. Kebutuhan tinggi tenaga akibat kehilangan tersebut dapat disimpulkan seperti berikut : (Thaha, 2006).

$$
h_{b c}=\mathrm{d}_{\mathrm{b}}(1-\varepsilon) \frac{\rho_{s}}{\rho}
$$

Dimana:

$\mathrm{H}_{\mathrm{bc}}=$ Kehilangan tinggi tenaga akibat lapisan sedimen $(\mathrm{cm})$

$\mathrm{d}_{\mathrm{b}}=$ Tebal Sedimen

$\rho=$ Rapat massa air

$\rho_{s}=$ Rapat massa sedimen

$\varepsilon \quad=$ Porositas sedimen

g = Percepatangravitasi $\left(\mathrm{m} / \mathrm{dtk}^{2}\right)$

\section{Aliran Laminer dan Turbulen}

Menurut hasil percobaan Reynold, untuk membedakan apakah aliran itu turbulen atau laminer dapat menggunakan bilangan tak berdimensi yang disebut dengan bilangan Reynold. Bilangan ini dihitung dengan persamaan berikut:

$\operatorname{Re}=\frac{p v D}{\mu}=\frac{V D}{v}$

Dimana:

Re=Bilangan Reynold (tak berdimensi)

$\mathrm{V}=$ Kecepatan rata-rata $(\mathrm{ft} / \mathrm{s}$ atau $\mathrm{m} / \mathrm{s}$ )

$\mathrm{D}=$ Diameter pipa (ft atau $\mathrm{m}$ )

$\mathrm{v}=$ Viskositas kinematik $\left(\mathrm{m}^{2} / \mathrm{s}\right)$

\section{Prinsip Dasar Transpor Sedimen}

\section{Dalam Pipa}


Transpor sedimen dalam pipa Tahap Penelitian

diperlukan dalam bidang pemindahan endapan lumpur dan pengerukan (dredging). Manfaat sistem ini dalam kedua bidang tersebut adalah untuk memindahkan sedimen/endapan pada minimum head loss tanpa pengendapan. Aspek penting dari syistem ini adalah bagaimana memprediksi head loss dan kecepatan minimum atau kecepatan kritis agar supaya pipa terhindar dari pengendapan. (Amrullah, 2010).

\section{METODE PENELITIAN}

\section{Lokasi dan Waktu Penelitian}

Penelitian ini dilakukan di Laboratorium Fakultas Teknik Universitas Muhammadiyah Makassar

\section{Jenis Penelitian}

Jenis penelitan yang digunakan adalah eksperimental, dimana penelitian tersebut dibuat dan dirancang sendiri oleh peneliti dengan berpedoman pada literatur-literatur yang berkaitan dengan flushing conduit, serta adanya kontrol dengan tujuan untuk mengetahui sebab akibat dari penggelontoran sedemen serta berapa besar pengaruh penggelontoan terhadap variasi sedimen.

\section{Persiapan}

Tahap pertama persiapan : Studi literatur dilakukan untuk mengumpulkan informasi-informasi yang berkaitan dengan masalah yang akan diteliti (flushing conduit). Sehingga dapat diketahui keadaan atau kedudukan masalah tersebut secara teoritas.

\section{Perancangan Model}

Perancangan model penelitian Flushing Conduit dilakukan terlebih dahulu agar dalam pembuatan model bisa lebih jelas dan berjalan sesuai rencana.

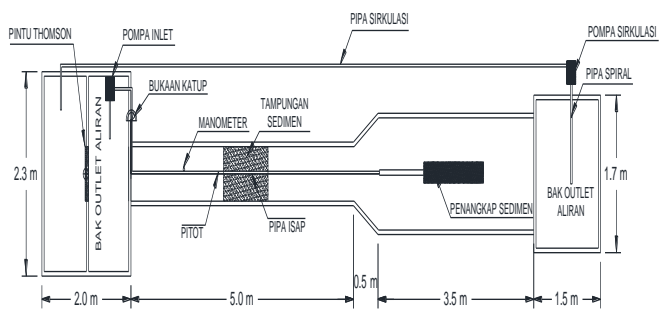

Gambar 2. Denah Flushing Conduit

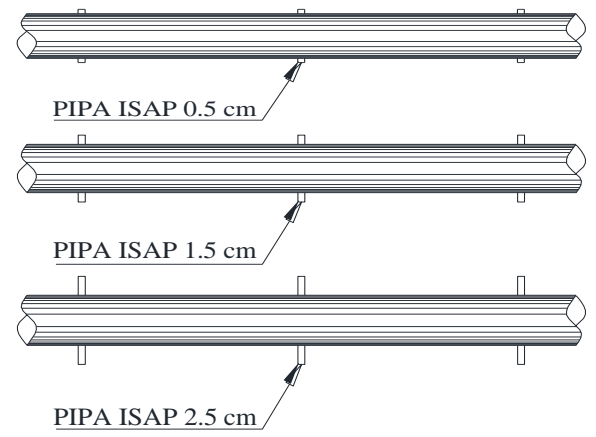

Gambar 3. Model Pipa Hisap

\section{Langkah-Langkah Penelitian}

Langkah-langkah dalam melakukan percobaan dalam penelitian : 
a) Menyiapkan model saluran terbuka dari pasangan batu dengan dimensi panjang saluran $9 \mathrm{~m}$, lebar saluran 1 $\mathrm{m}$, tinggi saluran $50 \mathrm{~cm}$. beserta perlengkapannya seperti pompa sirkulasi, pompa suplay, bak intlet (uk. $2.25 \mathrm{~m} \times 2.25 \mathrm{~m} \times 2 \mathrm{~m}$ ) sebagai suplay, bak outlet (uk. $1.5 \mathrm{~m}$ x $1.5 \mathrm{~m} \mathrm{x}$ $1 \mathrm{~m})$, dan saringan sebagai penampung sedimen yang tergelontor

b) Pipa Flushing PVC diameter (2.0 inci), dibuat lubang isap pada sisi kiri dan kanan sepanjang $50 \mathrm{~cm}$ dengan arah horizontal dengan diameter 12 $\mathrm{mm}$ dan berjumlah 6 buah pipa isap.

c) Pada Bak penyuplay air di pasang pintu ukur Thomson untuk mengukur debit aliran permukaan, dan pipa (suplay) dipasang alat ukur kecepatan air dan alat ukur tekanan air (Manometer). Selain itu dipasang pula stop kran sebelum air melewati pitot dan alat ukur tekanan air (Manometer). Pada pipa intlet juga dipasang sambungan dengan pompa untuk flushing konduit kemudian dipasang stop kran dan juga pipa pembuang di pasang sambungan dengan pompa untuk sirkulasi.

d) Menjalankan pompa untuk melaksanakan running awal dengan mengalirkan air tanpa pemberian sedimen untuk menentukan debit yang digunakan

e) Selanjuntya menjalankan pompa dengan mengalirkan air sesuai debit dan pemberian sedimen yang telah ditentukan

f) mengamati kondisi sedimen yang terhisap dan alat pengukur tekanan selama waktu yang telah ditentukan. Dalam hal ini waktu (t) dan panjang pipa isap yang digunakana divariasikan menjadi 3 macam.

g) Setelah variasi dan pembacaan tekanan selesai, selanjutnya mengukur banyaknya volume sedimen yang tergelontor.

h) Prosedur ini dilakukan dengan beberapa kali percobaan dimulai dari pipa isap $0,5 \mathrm{~cm}, 1,5 \mathrm{~cm}$ dan $2,5 \mathrm{~cm}$ untuk dijadikan bahan perbandingan.

\section{Flow Chart Penelitian}




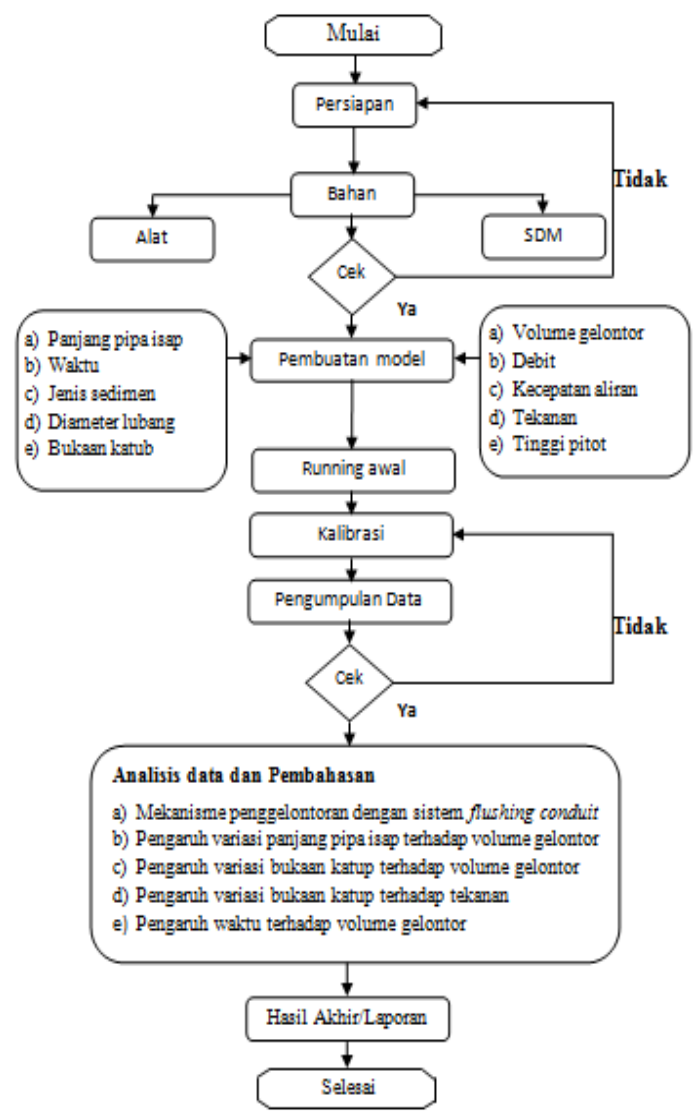

\section{Gambar 4. Flow Chart Penelitian}

\section{HASIL DAN PEMBAHASAN}

\section{Karakteristik Sedimen}

Karakteristik sedimen yang digunakan dalam penelitiuan ini adalah Pasir sedang, sesuai dengan hasil pemeriksaan ukuran butir dengan uji saringan dan gradasi ukuran butir, yang disajakian pada gambar dan tabel berikut.

Tabel 3. Data analisa saringan

\begin{tabular}{cccccc}
\hline \multirow{2}{*}{$\begin{array}{c}\text { Saringan Diameter } \\
\text { No. }\end{array}$} & $(\mathbf{m m})$ & $\begin{array}{c}\text { Berat } \\
\text { Tertahan } \\
\text { (gram) }\end{array}$ & $\begin{array}{c}\text { Kumulatif } \\
\text { (gram) }\end{array}$ & Tertahan & Lolos \\
\hline $\mathbf{4}$ & 4,76 & 4 & 4 & 0,4 & 99,6 \\
\hline $\mathbf{8}$ & 2,38 & 73 & 77 & 7,7 & 92,3 \\
\hline $\mathbf{1 6}$ & 1,19 & 236 & 313 & 31,3 & 68,7 \\
\hline $\mathbf{3 0}$ & 0,595 & 97 & 410 & 41 & 59 \\
\hline $\mathbf{5 0}$ & 0,297 & 453 & 863 & 86,3 & 13,7 \\
\hline $\mathbf{1 0 0}$ & 0,149 & 133 & 996 & 99,6 & 0,4 \\
\hline $\mathbf{2 0 0}$ & 0,074 & 4 & 1000 & 100 & 0 \\
\hline
\end{tabular}

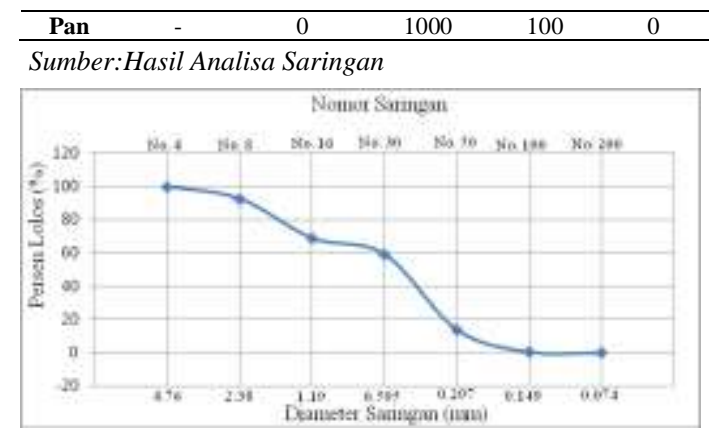

Gambar 5. Gradasi ukuran butiran sedimen (sampel)

\section{Pengaruh Panjang Pipa Isap Terhadap Volume Gelontor (Vg).}

Berdasarkan hasil data yang diperoleh maka dapat disimpulkan bahwa pengaruh panjang pipa isap terhadap volume penggelontoran adalah salah satu faktor yang mempegaruhi jumlah sedimen yang tergelontor dalam proses pengurasan metode flushing conduit.

Tabel 4. Pengaruh panjang pipa isap terhadap volume gelontor. $\mathrm{Q}_{1}=0,003$ $\mathrm{m}^{3} / \mathrm{dtk}$

\begin{tabular}{|c|c|c|c|}
\hline No & $\begin{array}{l}\text { Panjang } \\
\text { Pipa Isap } \\
\text { (cm) }\end{array}$ & $\begin{array}{c}\text { Waktu }(t) \\
(\text { menit })\end{array}$ & $\begin{array}{c}\text { Volume Gelontor } \\
(\mathbf{V g}) \\
\left(\mathrm{m}^{3}\right)\end{array}$ \\
\hline 1 & \multirow{3}{*}{0,5} & 3 & 0,0038 \\
\hline 2 & & 6 & 0,0050 \\
\hline 3 & & 9 & 0,0073 \\
\hline 4 & \multirow{3}{*}{1,5} & 3 & 0,0035 \\
\hline 5 & & 6 & 0,0042 \\
\hline 6 & & 9 & 0,0064 \\
\hline 7 & \multirow{3}{*}{2,5} & 3 & 0,0032 \\
\hline 8 & & 6 & 0,0041 \\
\hline 9 & & 9 & 0,0060 \\
\hline
\end{tabular}

Sumber:Hasil Perhitungan 


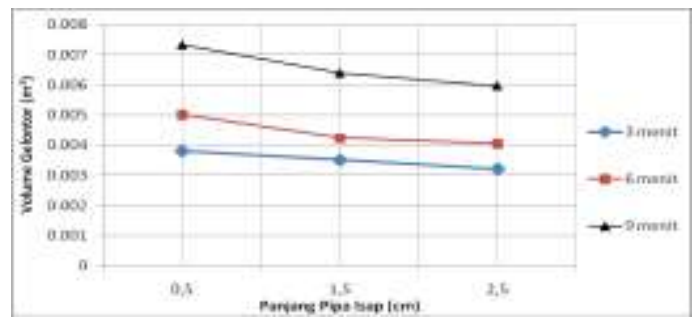

Gambar 6. Grafik pengaruh panjang pipa isap terhadap volume gelontor pada $Q_{1}=0,0030 \mathrm{~m}^{3} /$ dtk.

Tabel 5. Pengaruh panjang pipa isap terhadap volume gelontor. $\mathrm{Q}_{2}=0,0051$ $\mathrm{m}^{3} / \mathrm{dtk}$

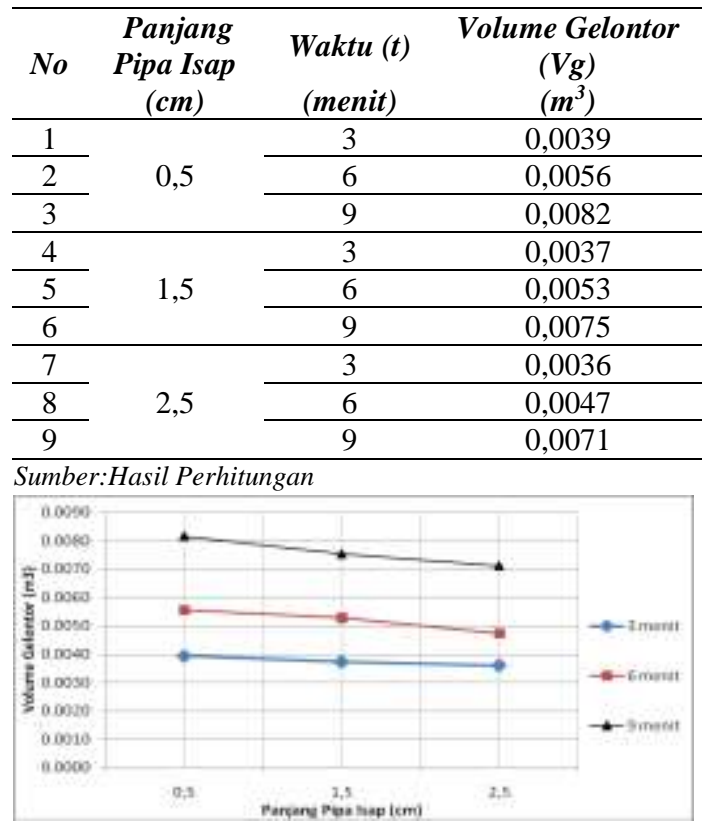

Gambar 7. Grafik pengaruh panjang pipa isap terhadap volume gelontor pada $Q^{2}=0,0051 \mathrm{~m}^{3} / \mathrm{dtk}$

Tabel 6. Pengaruh panjang pipa isap terhadap volume gelontor. $\mathrm{Q}_{3}=0,0079$ $\mathrm{m}^{3} / \mathrm{dtk}$

\begin{tabular}{|c|c|c|c|}
\hline No & $\begin{array}{l}\text { Panjang } \\
\text { Pipa Isap } \\
\quad(\mathrm{cm}) \\
\end{array}$ & $\begin{array}{c}\text { Waktu }(t) \\
\text { (menit) }\end{array}$ & $\begin{array}{c}\text { Volume Gelontor } \\
(\mathrm{Vg}) \\
\left(\mathrm{m}^{\mathbf{3}}\right) \\
\end{array}$ \\
\hline 1 & \multirow{3}{*}{0,5} & 3 & 0,0042 \\
\hline 2 & & 6 & 0,0062 \\
\hline 3 & & 9 & 0,0084 \\
\hline 4 & \multirow{3}{*}{1,5} & 3 & 0,0041 \\
\hline 5 & & 6 & 0,0059 \\
\hline 6 & & 9 & 0,0079 \\
\hline 7 & \multirow{3}{*}{2,5} & 3 & 0,0038 \\
\hline 8 & & 6 & 0,0053 \\
\hline 9 & & 9 & 0,0077 \\
\hline
\end{tabular}

Sumber:Hasil Perhitungan

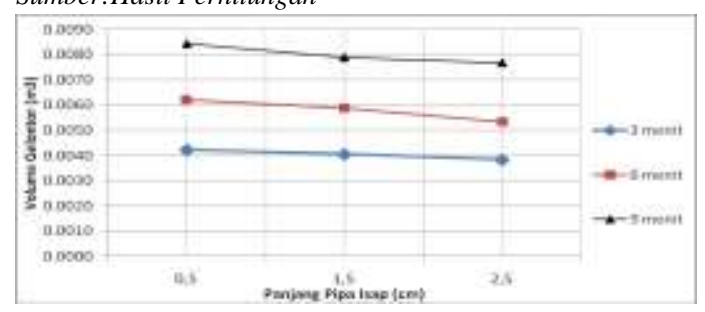

Gambar 8. Grafik pengaruh panjang pipa isap terhadap volume gelontor pada $Q 3=0,0079 \mathrm{~m}^{3} /$ dtk

Pengaruh Bukaan Katub Terhadap Volume Gelontor (Vg).

Pengaruh bukaan katub terhadap volume gelontor menunjukan bahwa semakin besar bukaan katub maka semakin banyak sedimen yang tergelontor.

Tabel 7. Pengaruh bukaan katub terhadap volume penggelontoran. Pipa isap berukuran $0,5 \mathrm{~cm}$

\begin{tabular}{|c|c|c|c|}
\hline No & $\begin{array}{c}\text { Bukaan } \\
\text { Katub } \\
\left({ }^{o}\right)\end{array}$ & $\begin{array}{c}\text { Waktu }(t) \\
\text { (menit) }\end{array}$ & $\begin{array}{c}\text { Volume } \\
\text { Gelontor }(\mathrm{Vg}) \\
\left(\mathrm{m}^{3}\right)\end{array}$ \\
\hline 1 & \multirow{3}{*}{45} & 3 & 0,0038 \\
\hline 2 & & 6 & 0,0050 \\
\hline 3 & & 9 & 0,0073 \\
\hline 4 & \multirow{3}{*}{60} & 3 & 0,0039 \\
\hline 5 & & 6 & 0,0056 \\
\hline 6 & & 9 & 0,0082 \\
\hline 7 & \multirow{3}{*}{90} & 3 & 0,0042 \\
\hline 8 & & 6 & 0,0062 \\
\hline 9 & & 9 & 0,0084 \\
\hline
\end{tabular}

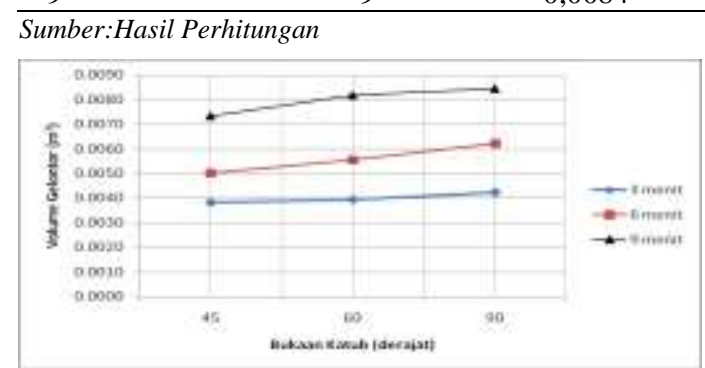

Gambar 9. Grafik pengaruh bukaan katub terhadap volume gelontor pada panjang pipa isap $0,5 \mathrm{~cm}$ 
Tabel 8. Pengaruh bukaan katub terhadap volume penggelontoran. Pipa isap berukuran $1,5 \mathrm{~cm}$

\begin{tabular}{|c|c|c|c|c|}
\hline No & $\begin{array}{c}\text { Bukaan } \\
\text { Katub } \\
\left({ }^{o}\right)\end{array}$ & $\begin{array}{c}\text { Waktu }(t) \\
\text { (menit) }\end{array}$ & & $\begin{array}{l}\text { lume } \\
\text { tor }(V g) \\
\left.m^{3}\right)\end{array}$ \\
\hline 1 & \multirow{3}{*}{45} & 3 & \multicolumn{2}{|c|}{0,0035} \\
\hline 2 & & 6 & \multicolumn{2}{|c|}{0,0042} \\
\hline 3 & & 9 & \multicolumn{2}{|c|}{0,0064} \\
\hline 4 & \multirow{3}{*}{60} & 3 & \multicolumn{2}{|c|}{0,0037} \\
\hline 5 & & 6 & \multicolumn{2}{|c|}{0,0053} \\
\hline 6 & & 9 & \multicolumn{2}{|c|}{0,0075} \\
\hline 7 & \multirow{3}{*}{90} & 3 & \multicolumn{2}{|c|}{0,0041} \\
\hline 8 & & 6 & \multicolumn{2}{|c|}{0,0059} \\
\hline 9 & & 9 & \multicolumn{2}{|c|}{0,0079} \\
\hline \multicolumn{5}{|c|}{ Sumber:Hasil Perhitungan } \\
\hline \multicolumn{5}{|c|}{$a 0000$} \\
\hline \multirow{6}{*}{ 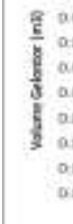 } & & & & \multirow{6}{*}{ 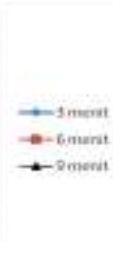 } \\
\hline & & & & \\
\hline & :- & (t) & & \\
\hline & & & & \\
\hline & & & & \\
\hline & as & & & \\
\hline
\end{tabular}

Gambar 10. Grafik pengaruh bukaan katub terhadap volume gelontor pada panjang pipa isap $1,5 \mathrm{~cm}$

Tabel 9. Pengaruh bukaan katub terhadap volume penggelontoran. Pipa isap berukuran $2,5 \mathrm{~cm}$.

\begin{tabular}{|c|c|c|c|c|}
\hline No & $\begin{array}{c}\text { Bukaan } \\
\text { Katub } \\
\left({ }^{o}\right)\end{array}$ & $\begin{array}{c}\text { Waktu (t) } \\
\text { (menit) }\end{array}$ & & $\begin{array}{l}\text { ume } \\
\text { tor }(\operatorname{Vg}) \\
\left.n^{3}\right)\end{array}$ \\
\hline 1 & \multirow{3}{*}{45} & 3 & \multicolumn{2}{|c|}{0,0032} \\
\hline 2 & & 6 & \multicolumn{2}{|c|}{0,0041} \\
\hline 3 & & 9 & \multicolumn{2}{|c|}{0,0060} \\
\hline 4 & \multirow{3}{*}{60} & 3 & \multicolumn{2}{|c|}{0,0036} \\
\hline 5 & & 6 & \multicolumn{2}{|c|}{0,0047} \\
\hline 6 & & 9 & \multicolumn{2}{|c|}{0,0071} \\
\hline 7 & \multirow{3}{*}{90} & 3 & \multicolumn{2}{|c|}{0,0038} \\
\hline 8 & & 6 & \multicolumn{2}{|c|}{0,0053} \\
\hline 9 & & 9 & \multicolumn{2}{|c|}{0,0077} \\
\hline \multicolumn{5}{|c|}{ Sumber:Hasil Perhitungan } \\
\hline \multicolumn{5}{|c|}{00050} \\
\hline \multirow{6}{*}{ 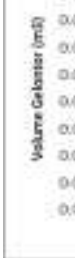 } & & & & \multirow{6}{*}{ 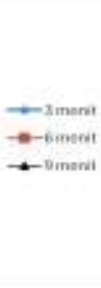 } \\
\hline & & & & \\
\hline & & + & & \\
\hline & & & & \\
\hline & & & & \\
\hline & 4s & an Kotub iderajar & & \\
\hline
\end{tabular}

Gambar 11. Grafik pengaruh bukaan katub terhadap volume gelontor pada panjang pipa isap $2,5 \mathrm{~cm}$
Pengaruh Bukaan Katub Terhadap Tekanan.

Pengaruh bukaan katub terhadap tekanan menunjukan bahwa semakin besar bukaan katub maka tekanan yang dihasilkan semakin besar, hal ini dipengaruhi oleh debit yang berbeda dari stiap bukaaan katubnya.

Tabel 10. Pengaruh bukaan katub terhadap tekanan. Pipa isap berukuran $0,5 \mathrm{~cm}$.

\begin{tabular}{|c|c|c|c|}
\hline No & $\begin{array}{c}\text { Bukaan } \\
\text { Katub } \\
\left({ }^{o}\right)\end{array}$ & $\begin{array}{c}\text { Waktu }(t) \\
(\text { menit })\end{array}$ & $\begin{array}{c}\text { Tekanan }(P) \\
\left(\mathrm{kg} / \mathrm{cm}^{2}\right) \\
\end{array}$ \\
\hline 1 & \multirow{3}{*}{45} & 3 & 0,0680 \\
\hline 2 & & 6 & 0,0683 \\
\hline 3 & & 9 & 0,0690 \\
\hline 4 & \multirow{3}{*}{60} & 3 & 0,0731 \\
\hline 5 & & 6 & 0,0748 \\
\hline 6 & & 9 & 0,0755 \\
\hline 7 & \multirow{3}{*}{90} & 3 & 0,0796 \\
\hline 8 & & 6 & 0,0806 \\
\hline 9 & & 9 & 0,0833 \\
\hline
\end{tabular}

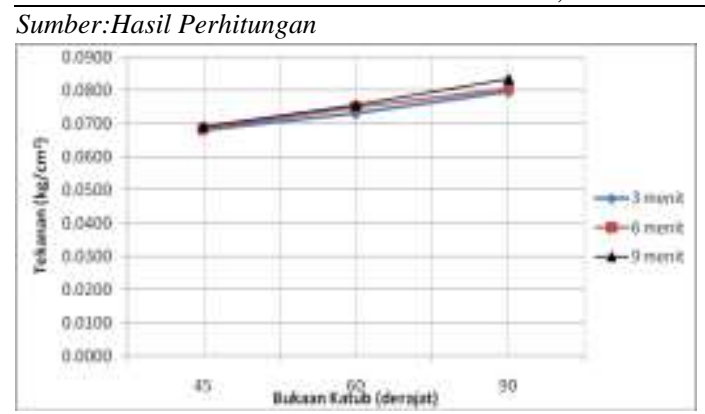

Gambar 12. Grafik pengaruh bukaan katub terhadap tekanan pada panjang pipa isap $0,5 \mathrm{~cm}$

Tabel 11. Pengaruh bukaan katub terhadap tekanan. Pipa isap berukuran $1,5 \mathrm{~cm}$

\begin{tabular}{|c|c|c|c|}
\hline No & $\begin{array}{c}\text { Bukaan } \\
\text { Katub } \\
\left(^{o}\right)\end{array}$ & $\begin{array}{c}\text { Waktu }(t) \\
\text { (menit) }\end{array}$ & $\begin{array}{c}\text { Tekanan }(P) \\
\left(\mathrm{kg} / \mathrm{cm}^{2}\right)\end{array}$ \\
\hline 1 & \multirow{3}{*}{45} & 3 & 0,0554 \\
\hline 2 & & 6 & 0,0585 \\
\hline 3 & & 9 & 0,0605 \\
\hline 4 & \multirow{2}{*}{60} & 3 & 0,0643 \\
\hline 5 & & 6 & 0,0670 \\
\hline
\end{tabular}




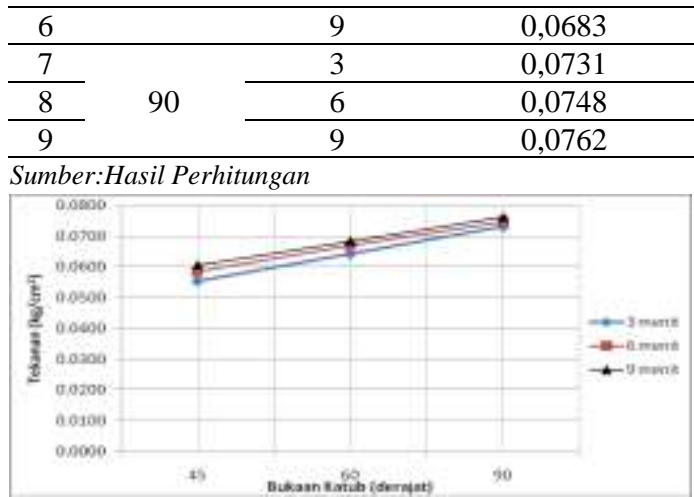

Gambar 13. Grafik pengaruh bukaan katub terhadap tekanan pada panjang pipa isap $1,5 \mathrm{~cm}$

Tabel 12. Pengaruh bukaan katub terhadap tekanan. Pipa isap berukuran $2,5 \mathrm{~cm}$

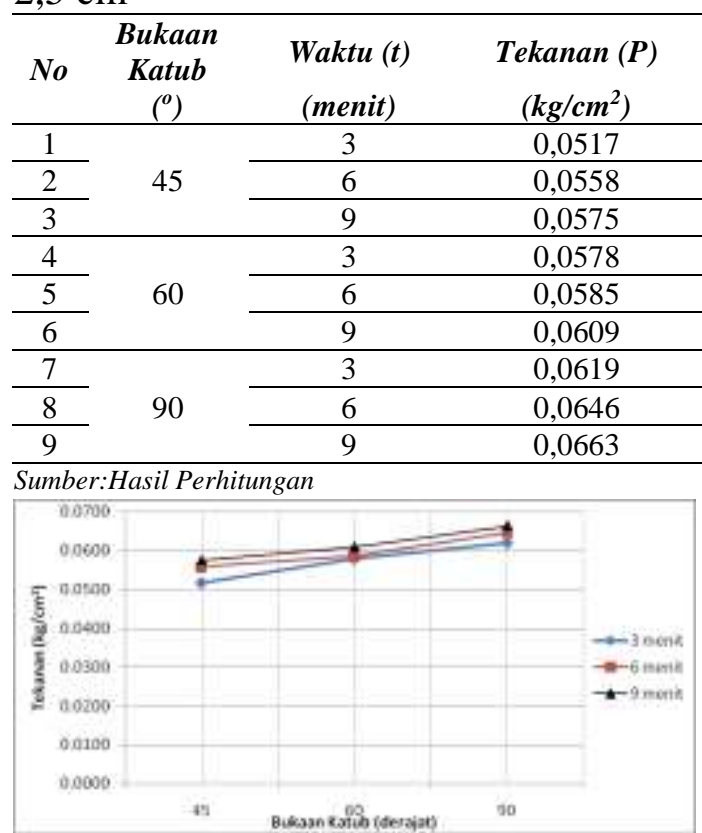

Gambar 14. Grafik pengaruh bukaan katub terhadap tekanan pada panjang pipa isap $2,5 \mathrm{~cm}$

\section{Pengaruh Waktu Terhadap Volume}

\section{Gelontor.}

Pengaruh waktu terhadap volume gelontor menunjukan bahwa semakin lama waktu yang diberikan maka volume gelontor yang dihasilkan semakin besar.

Tabel 13. Pengaruh waktu terhadap volume gelontor. Pipa isap berukuran $2,5 \mathrm{~cm}$

\begin{tabular}{|c|c|c|c|}
\hline No & $\begin{array}{l}\text { Waktu } \\
\text { (menit) }\end{array}$ & $\begin{array}{c}\text { Pipa Isap } \\
(\mathrm{cm})\end{array}$ & $\begin{array}{c}\text { Volume gelontor } \\
\left(\mathrm{m}^{3}\right)\end{array}$ \\
\hline 1 & 3 & \multirow{3}{*}{0,5} & 0,0038 \\
\hline 2 & 6 & & 0,0050 \\
\hline 3 & 9 & & 0,0073 \\
\hline 4 & 3 & \multirow{3}{*}{1,5} & 0,0035 \\
\hline 5 & 6 & & 0,0042 \\
\hline 6 & 9 & & 0,0064 \\
\hline 7 & 3 & \multirow{3}{*}{2,5} & 0,0032 \\
\hline 8 & 6 & & 0,0041 \\
\hline 9 & 9 & & 0,0060 \\
\hline
\end{tabular}

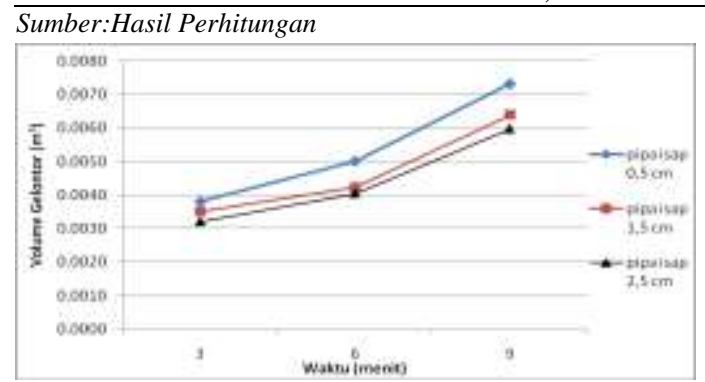

Gambar 15. Grafik pengaruh waktu terhadap volume gelontor pada durasi waktu 3 menit

Tabel 14. Pengaruh waktu terhadap volume gelontor pada durasi waktu 6 menit

\begin{tabular}{|c|c|c|c|}
\hline No & $\begin{array}{c}\text { Waktu } \\
\text { (menit) }\end{array}$ & $\begin{array}{c}\text { Pipa Isap } \\
(\mathrm{cm})\end{array}$ & $\begin{array}{c}\text { Volume gelontor } \\
\left(\mathrm{m}^{3}\right)\end{array}$ \\
\hline 1 & 3 & \multirow{3}{*}{0,5} & 0,0039 \\
\hline 2 & 6 & & 0,0056 \\
\hline 3 & 9 & & 0,0082 \\
\hline 4 & 3 & \multirow{3}{*}{1,5} & 0,0037 \\
\hline 5 & 6 & & 0,0053 \\
\hline 6 & 9 & & 0,0075 \\
\hline 7 & 3 & \multirow{3}{*}{2,5} & 0,0036 \\
\hline 8 & 6 & & 0,0047 \\
\hline 9 & 9 & & 0,0071 \\
\hline
\end{tabular}




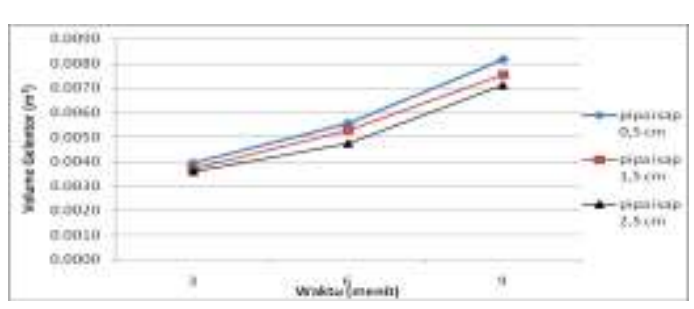

Gambar 16. Grafik pengaruh waktu terhadap volume gelontor pada durasi waktu 6 menit

Tabel 15. Pengaruh waktu terhadap volume gelontor pada durasi waktu 9 menit

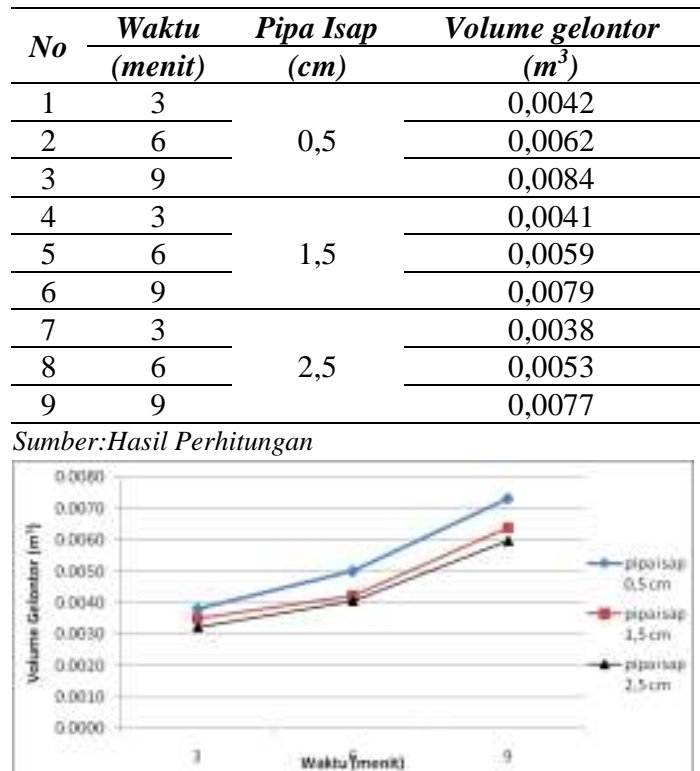

Gambar 17. Grafik pengaruh waktu terhadap volume gelontor pada durasi waktu 9 menit

\section{PENUTUP}

\section{Kesimpulan}

1) Hasil penelitian menunjukan pada panjang pipa isap $0,5 \mathrm{~cm}$ menghasilkan volume gelontor sedimen yang lebih besar dibandingkan pada pipa isap 1,5 cm dan $2,5 \mathrm{~cm}$. Hal ini disebabkan oleh perubahan tekanan dari dalam pipa yang menurun jika menggunakan pipa isap yang lebih pendek, sehingga sedimen lebih mudah masuk kedalam pipa karena tekanan dari sedimen yang besar.

2) Pengaruh bukaan katub terhadap volume gelontor yaitu semakin besar derajat bukaan katub maka semakin banyak jumlah sedimen yang tergelontor. Hal ini disebabkan oleh debit yang semakin bertambah jika derajat bukaan katubnya diperbesar.

\section{Saran}

1) Untuk mendapatkan tekanan yang stabil diperlukan mesin pompa yang memiliki tekanan yang lebih stabil.

2) Untuk penelitian selanjutnya tidak perlu menggunakan variasi bukaan katub, jadi katub pada pipa dapat dihilangkan.

3) Tersumbatnya sedimen di dalam pipa isap membuat proses penggelontoran sedimen menjadi kurang maksimal, sehingga diharapkan pada penelitian selanjutnya untuk menggunakan pipa isap yang lebih besar guna memaksimalkan proses penggelontoran sedimen.

\section{DAFTAR PUSTAKA}

Alimuddin L,Aisyah. (2012). Pendugaan Sedimentasi pada DAS Mamasa di Kab. Mamasa Propinsi Sulawesi Selatan. 
Fakultas Pertanian Unhas. Muchsin. Dan Subgyo, Rachmat. Makassar (2011). Kaji Eksperimental Amrullah. (2010). Studi Kinerja Koefisien Kerugian Pada Flushing Conduit Sebagai Alat Percabangan Pipa Dengan Sudut Penguras Endapan Sedimen $45^{\circ}, 60^{\circ}$ dan $90^{\circ}$. Jurusan Teknik Muara Dengan Experimen Laboratorium. Program Pascasarjana Universitas hasanuddin. Makassar

Asdak, Chay. (2010). Hidrologi dan pengelolaan Daerah Aliran Sungai:Edisi Revisi Kelima. Yogyakarta: Gadjah Mada Press Yogyakarta

Hakim, Fajar Aldoko. (2016). Analisis Sebaran Sedimendan Efektifitas Tampungan Menggunakan Teknik Interpolasi Ruang (Studi Kasus Penggelontoran Waduk Wlingi Dan Waduk Lodoyo. Fakultas Teknik Universitas Brawijaya. Malang

Hakim, Siti Riskayanti. (2015). Studi Laju Sedimentasi Waduk Bili-Bili Pasca Pengembangan Bangunan Penahan Sedimen. Fakultas Teknik Universitas Hasanuddin. Makassar

Ismali, Ahmad Ghufron. (2012). Analisis Angkutan Sedimen Bengawan Solo Ruas SerenanCерu. Jurusan Teknik Sipil Universitas Sebelas Maret. Surakarta

Lubis, Astika Murni. (2016). Analisis Sedimentasi Sungai Way Besar. Fakultas Teknik Universitas Lampung Mesin Fakultas Teknik Universitas Tadulako

Suroso. Dan Widiyanto, Wahyu. (2009). Model Pengendalian Sedimentasi Waduk Mrica Dengan Fluidasi. Program Studi Teknik Sipil Unsoed. Purwokerto Indonesia

Sinatala, Arsyad. (2010). Edisi kedua: konservasi tanah dan air. Bogor : Institut Pertanian Bogor

Sudaryono (2012). Pengelolaan Daerah aliran sungai (DAS) Terpadu, Konsep pembangunan berkelanjutan. Jurnal Teknologi Lingkungan, Vol.3, No. 2, Mei 2012: 153-158

Teguh Marhendi (2013). Strategi Pengelolaan Sedimenyasi Waduk. Program Studi Fakultas Teknik Universitas Muhammadiyah Purwokerto

Triatmada, R., 2009. Hidraulika Sistem Perpipaan Air Minum. Beta offset.Yogyakarta.

Wijaya, Khamid. (2011). Dampak Perubahan Penggunaan Lahan Di DAS Gung Hulu Terhadap Debit Sungai Gung Kabupaten Tegal. Universitas Negeri Semarang. 